\title{
Classical VEGF, Notch and Ang signalling in cancer angiogenesis, alternative approaches and future directions (Review)
}

\author{
NUNZIA CAPORARELLO*, GABRIELLA LUPO*, MELANIA OLIVIERI, MARTINA CRISTALDI, \\ MARIA TERESA CAMBRIA, MARIO SALMERI and CARMELINA DANIELA ANFUSO \\ Department of Biomedical and Biotechnological Sciences, University of Catania, I-95123 Catania, Italy
}

Received April 5, 2017; Accepted May 16, 2017

DOI: $10.3892 / \mathrm{mmr} .2017 .7179$

\begin{abstract}
Angiogenesis is the formation of new vessels starting from pre-existing vasculature. Tumour environment is characterized by 'aberrant angiogenesis', whose main features are tortuous and permeable blood vessels, heterogeneous both in their structure and in efficiency of perfusion and very different from normal vessels. Therapeutic strategies targeting the three pathways chiefly involved in tumour angiogenesis, VEGF, Notch and Ang signalling, have been identified to block the vascular supply to the tumour. However, phenomena of toxicity, development of primary and secondary resistance and hypoxia significantly blunted the effects of anti-angiogenic drugs in several tumour types. Thus, different strategies aimed to overcome these problems are imperative. The focus of the present review was some principal 'alternative' approaches to classic antiangiogenic therapies, including the cyclooxygenase-2 (COX-2) blockade, the use of oligonucleotide complementary to the miRNA to compete with the mRNA target (antimiRs) and the inhibition of matrix metalloproteinases (MMPs). The role of blood soluble VEGFA as a predictive biomarker during antiangiogenic therapy in gastric, ovarian and colorectal cancer was also examined.
\end{abstract}

\section{Contents}

1. Introduction

2. Current status and therapeutic targets: VEGF, Notch and angiopoietin signaling

3. Alternative approaches towards new antitumour vascularization therapies

Correspondence to: Professor Carmelina Daniela Anfuso, Department of Biomedical and Biotechnological Sciences, University of Catania, Biological Tower, via S. Sofia 97, I-95123 Catania, Italy E-mail: daniela.anfuso@unict.it

${ }^{*}$ Contributed equally

Key words: tumour angiogenesis, endothelial cells, vascular endothelial growth factor receptors, Notch, angiopoietin, cyclooxygenase-2, miRNA, matrix metalloproteinases
4. VEGFA as a soluble biomarker in antiangiogenic therapy

5. Future directions

6. Conclusions

\section{Introduction}

The blood vessels supplying tumours are particularly permeable, tortuous and greatly different from those composing the normal vasculature. These features, including the heterogeneity in their morphological structure and the efficiency of tissue perfusion, determine what is currently known as 'aberrant angiogenesis', which characterizes the tumour environment (1). Primary solid tumours originate close to pre-existing tissue vasculature, initially growing along such tissue blood vessels (vessel co-option), and this phenomenon is particularly important for the metastatic potential which frequently occurs in highly vascularized tissues (2).

Folkman first suggested the importance of establishing anti-angiogenic therapies within the clinical context aimed to investigate drugs and anti-cancer therapies. The angiogenic sprouting from the surrounding vasculature induced by the growing cancer is essential, in order to provide the oxygen and nutrient supply for the tumour to grow beyond 2-3 mm (3) (Fig. 1). In addition, the newborn vasculature activates angiocrine signallings through the secretion of growth factors, which stimulate the growth of adjacent tumour cells. This mechanism has highlighted new potential therapeutic targets (4).

Tumour angiogenesis involves an intricate molecular cross-talk between the tumour and the surrounding cells, such as endothelial cells (EC), pericytes (PC), fibroblasts, smooth muscle cells, and tumour-associated macrophages (5). It has been shown that both tumour suppressor genes and oncogene mutations lead to the switching into the angiogenic feature tumour, with a consequent endogenous imbalance between pro-angiogenic and anti-angiogenic factors in favour of angiogenesis (6-8).

2. Current status and therapeutic targets: VEGF, Notch and Angiopoietin signalling

Vascular endothelial growth factor (VEGF) family. VEGF family and their cognate receptors are the leading molecular 

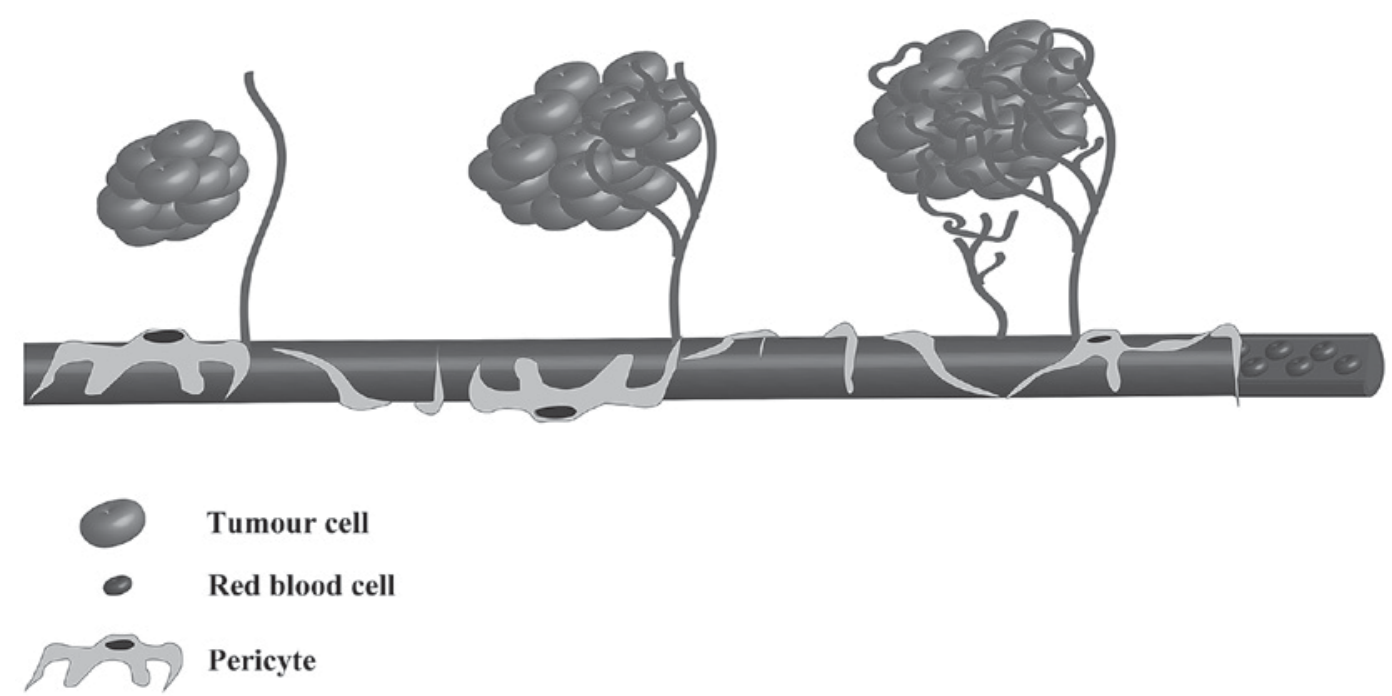

Figure 1. Sprouting angiogenesis in tumour growth. Cancer cells satisfy their increasing need for oxygen and nutrients releasing angiogenic factors that attract inflammatory and endothelial cells and promote their proliferation and sprouting. The new blood flow sustains tumour growth and metabolism.

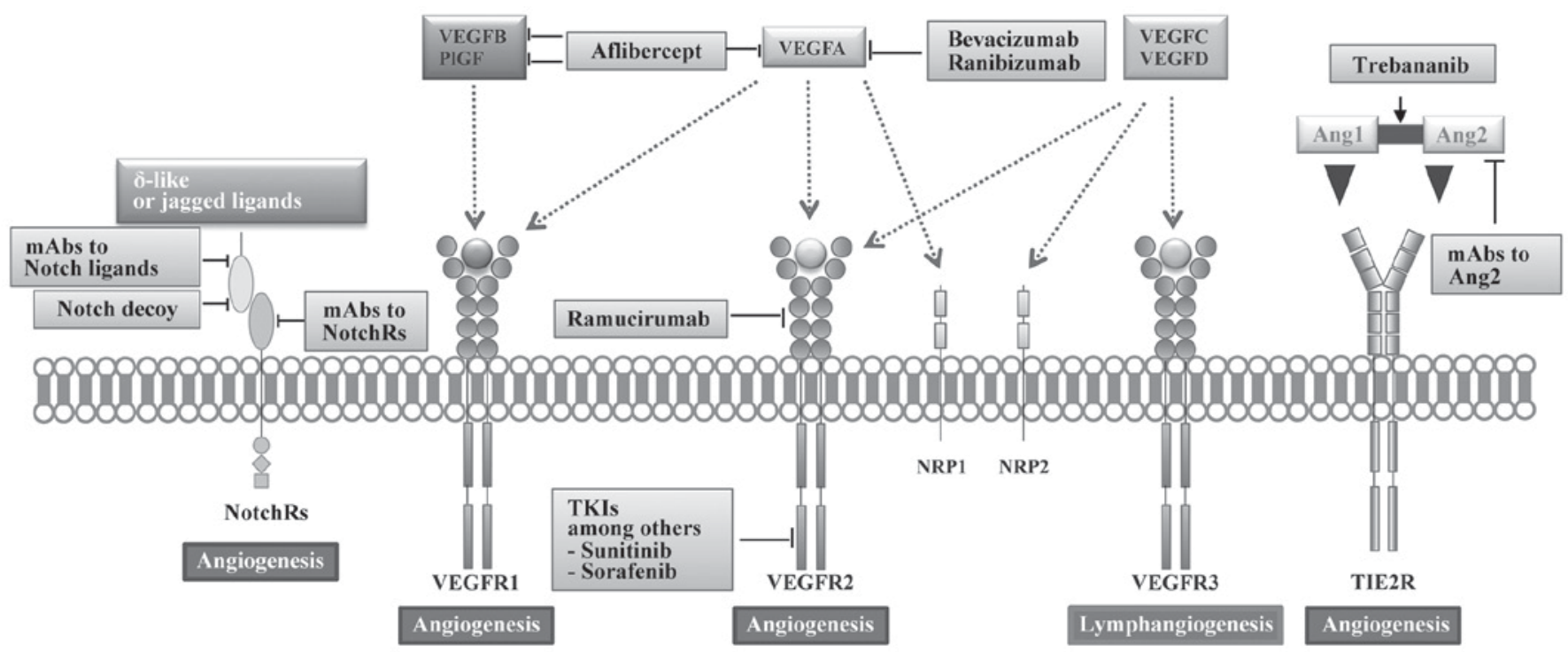

Figure 2. Antiangiogenic therapy targets involving VEGF, Notch and Ang pathways. Angiogenesis and vascular permeability are regulated by VEGFA through the activation of two receptors, VEGFR1 and VEGFR2. VEGFB and PIGF selectively switch on VEGFR1. Bevacizumab and ranibizumab bind VEGFA, as well as aflibercept, which also binds VEGFB and PIGF, thus inhibiting VEGFA-induced signalling. Small molecules multi-targeted tyrosine kinase inhibitor, such as sunitinib and sorafenib, are able to inhibit the VEGFR2 pathways. Furthermore, ramucirumab blocks the receptor directly. In addition, the angiogenic stimulus can be regulated by Notch-receptors and TIE2-receptors. Other approaches involve the use of monoclonal antibodies directed to Notch and TIE2 receptors. Additionally, VEGFC and VEGFD activate VEGFR3, stimulating lymphangiogenesis. VEGF, vascular endothelial growth factor.

players in tumour angiogenesis. The family comprises VEGFA, VEGFB, VEGFC, VEGFD, and placental growth factor (PlGF) (Fig. 2). The principal mediators of tumour angiogenesis, both of which are VEGFA isoforms, are the soluble VEGF121, and VEGF165, which are also secreted, although a significant fraction remains bound to the cell surface and the matrix extracellular heparan sulphate. The main signalling tyrosine kinase receptor (TKR) is VEGF receptor 2 (VEGFR2; FLK, KDR in humans). Two other VEGF-TKRs include VEGFR1 (FLT1) and VEGFR3 (FLT3). VEGFR1 functions as a traditional TKR or a 'decoy' receptor. Its affinity for the growth factor is high, whereas kinase activity is weak, preventing VEGF from binding to VEGFR2. VEGFR3 is mostly involved in lymphangiogenesis and has a minor role in vascular angiogenesis (9). The PlGF and VEGFB (VEGF-related molecules) bind selectively to VEGFR1, while VEGFA binds VEGFR1 and VEGFR2. VEGFC and VEGFD bind to VEGFR3, and, following a proteolytic processing, activate VEGFR2 after binding (10). VEGF isoforms and PIGF also bind to the non-TK co-receptors neuropilin NRP1 (11) and NRP2. NRP1, in turn, increases the binding affinity to VEGFR2. It has been reported that VEGF and PlGF could have direct effects on NRP1, independently from the VEGF receptor (12). The VEGFR1 may also regulate the expression of a variety of genes in the endothelium, including matrix metalloproteinase-9 (MMP-9) and growth factors, such as hepatocyte growth factor and connective tissue growth factor, which are known to play important 
roles in tissue regeneration and homeostasis (13). EC, monocytes, macrophages and, in some cases, tumour cells express VEGFR1, which can mediate tumour proliferation in response to VEGF or PlGF (14). The VEGFR1 mediates signals towards the angiogenic process (through VEGF and PIGF binding), the fatty acid uptake (via VEGFB) and immune cell recruitment after VEGF binding. As mentioned, lymphatic endothelium highly expresses VEGFR3 and the activation of this TKR by VEGFC and VEGFD stimulates the process of lymphangiogenesis. VEGFR2 is primarily expressed in EC, and the signalling of VEGF through this receptor is the major driver of angiogenesis. Evidence suggested that VEGFC and VEGFD are also involved in VEGFR2-mediated angiogenesis $(15,16)$.

The most critical driver of tumour angiogenesis is the activation of VEGFR2 by VEGF (17). The molecular mechanisms that regulate and result from this event have been reported in a number of reviews. The VEGF knockout/knockdown in tumour cells significantly prevents their ability to grow and spread $(18,19)$.

Once activated, the VEGFR2 switches on the canonical TKRs signalling pathways $(20,21)$. The Y1504 and Y1509 autophosphorylation VEGFR2 kinase domain is one of the earliest events following the binding of growth factors and is crucial for downstream kinase activations and subsequent phosphorylation events on the VEGFR2. As a result of this, a number of VEGFR2 kinase activity small molecule inhibitors have been developed as effective drugs to treat various cancer types.

Other tyrosine residues on VEGFR2 outside the kinase domain are phosphorylated in response to VEGF binding, of which Y951, Y1175 and Y1214 are the most important. All of these mediate endothelial migration, as well as Y951- and Y1175-mediating endothelial permeability and proliferation, respectively. The establishment of these intracellular complexes on VEGFR2 culminates in activation of traditional pathways such as PI3K, PKC and RAS/RAF/ERK/MAPK.

VEGFC and VEGFD bind to and signal through VEGFR2, and their single knockout phenotypes suggest that they play an important role in lymphangiogenesis $(22,23)$. The knockout of VEGFC and VEGFD had no effects on blood vessel development (24). This fact demonstrated that VEGFA is able to promote angiogenesis through VEGFR2 during development. The VEGFA gene is under the direct control of hypoxia inducible transcription factors $1 \mathrm{~A}$ and $2 \mathrm{~A}$ (HIF1A and HIF2A) $(25,26)$. This assumption provided the basis for understanding the interplay between tumour growth, angiogenesis and metabolism (5).

The canonical pathway for a therapeutic intervention in cancer involves VEGF/VEGFR2 signalling inhibition, leading to the development of a generation of neutralizing antibodies to VEGF. The humanized anti-VEGF mAb bevacizumab (avastin) binds to and neutralizes all human VEGFA isoforms and their proteolytic fragments specifically (27). At present, bevacizumab has been approved for metastatic colorectal cancer (in combination with chemotherapy) (28), metastatic non-squamous non-small cell lung cancer (29), glioblastoma (30), metastatic renal cell carcinoma (in combination with IFN $\alpha$ ) (31), as well as for platinum-resistant ovarian cancer (32) and metastatic cervical cancer (33). The VEGFtrap aflibercept, is a recombinant decoy receptor fusion protein formulated by the fusion of the VEGFR1-domain 2 and the VEGFR2-domain 3 with the Fc portion of human IgG1 which binds the different isoforms of VEGFA, VEGFB and PIGF $(34,35)$. Aflibercept showed a higher affinity for VEGF compared to VEGFR2 or bevacizumab (36) and, in combination with chemotherapy, it has been approved for the second-line treatment of metastatic colorectal cancer (37). In the therapeutic intervention in cancer, small molecules, which selectively inhibit the intrinsic tyrosine kinase activity of the catalytic binding site on the VEGFR2 intracellular domain, were introduced (TKIs), such as sunitinib (competitive inhibitor), sorafenib (allosteric inhibitor), vandetanib (covalent inhibitor), currently known as 'first generation' of anti-angiogenic TKIs. In addition to the VEGFRs, they inhibit a wide range of kinase targets such as B-Raf, c-kit, PDGFRs, FLT3, CSF1R, RET (38). The 'second generation' of TKIs (cediranib, tivozanib, axitinib, pazopanib) have improved the selectivity and the efficiency for VEGFRs (39), and have been approved by the FDA in solid tumours such as gastrointestinal stromal tumours (40), hepatocellular carcinoma (41), metastatic renal cell carcinoma (42), advanced medullary thyroid cancer (43), pancreatic tumours (44), and advanced soft tissue sarcoma (45). Ramucirumab (IMC-1121B) is a fully-human IgG1 mAb that binds to the ligand-binding site of VEGFR2, thus preventing its activation. Following extensive clinical testing programmes (46-51), ramucirumab received approval for its use in metastatic gastric/gastroesophageal junction adenocarcinoma (monotherapy and in combination with chemotherapy), in metastatic colorectal cancer and in metastatic non-small cell lung cancer (in combination with chemotherapy) (52).

Ligands of Notch receptors. The Notch receptor-ligand system is a pivotal path mediating tumour angiogenesis. In mammals, this signalling pathway involves four Notch receptors (Notch1, $2,3,4)$ and five Notch ligands [ $\delta$-like ligands (Dll1, Dll3, Dl14) and Jagged 1, 2] (Fig. 2) (53). EC express all ligands, except Dl13 (expressed mainly from tumour cells but not in normal adult tissues) and Notch1, 2 and 4 receptors (54). Notch3 is expressed in a wide variety of tissues during development, but in adult tissues it is mainly expressed in the smooth vascular muscle cells. Notch signalling is vital for endothelial sprouting and the formation of tip and stalk EC. Following VEGF stimulation, tip EC begins to upregulate Dll4, which then binds to the Notch receptor on adjacent EC. This event causes VEGFR1 and 2 downregulation and formation of the peculiar stalk cell phenotype (55). The vessels of human tumours and tumour xenografts overexpress Dll4, suggesting a therapeutic target for anti-angiogenic strategies $(56,57)$.

D114 blockade by using monoclonal antibodies is anti-angiogenic, and has previously shown anti-tumour effects in six tumour models (58). As a result of two different studies, the inhibition of Notch-Dll4 protein interaction was carried out by the use of a soluble Dll4 ECD fused to an Fc tag (D114-ECD-Fc), and this approach caused coincident effects on tumour angiogenesis with the antibody blocking strategy $(59,60)$. By using the whole of the Notch1 ECD fused to an Fc tag (Notch1 decoy), soluble versions of the Notch1 receptor have been developed, with significant anti-angiogenic effects in mouse tumour xenografts (61). Recently, Notch decoy molecules containing domains for the binding to Dll1/Dll4, 
Jagged or both have been created and are in the early-phase of clinical trials (62). The inhibitors of $\gamma$-secretase targeting Notch activation lead to gastrointestinal side effects, and for this reason their use is restricted (63).

Angiopoietins/TIE axis. Among the molecules and their respective activated pathways that contribute to tumour angiogenesis the four members of the angiopoietin family (Ang), which bind to the tyrosine kinase receptors TIE1 and TIE2 (64), must be included (Fig. 2). Both Ang1 and Ang2 activate the EC membrane receptor tyrosine kinase TIE2. Ang1 mediates vessel development and maturation, and probably is involved in the stabilization and protection of the existing vasculature (65). During development, Ang2 is mostly present in the tissues that require a vascular remodelling. It is highly expressed in cancer: an altered ratio Ang2/Ang1 in favour of the latter markedly increases the angiogenic process (66). It has been suggested that Ang2 is associated with the predisposition of the endothelium towards the angiogenic status necessary for the angiogenic switch on and vascular destabilization (67). In order to formulate antiangiogenic drugs, agents targeting the Ang2-TIE2 axis have been taken into consideration.

The antibodies against Ang2 developed by Medimmune (MEDI3617) (68) and Regeneron (REGN910) (69) inhibit the growth of xenograft tumours in both cases and effects were enhanced when coupled to the VEGF blockade. The two agents are currently undergoing phase I clinical trials. In addition, the double specific antibody against Ang2 and VEGF caused a complete tumour regression in a wide range of tumour xenograft models, showing anti-metastatic and anti-angiogenic properties (70). The other approach towards the inhibition of Ang-TIE2 interaction is the use of 'peptibody' such as trebananib. It is a peptide-Fc fusion that comprises two peptides blocking Ang2 and Ang1 from interacting with TIE2 receptor, and inhibits rat corneal vascularisation and colorectal xenograft tumour growth (71), although it showed disappointing results in clinical trial phase III for ovarian cancer, as recently reported (72). A specific A TIE2-ECD-Fc ligand trap such as the specific and high cognate Ang2 inhibitor was developed (73).

\section{Alternative approaches towards new antitumour vascularization therapies}

Despite the efficacy of 'classic' antiangiogenic therapies in association with chemotherapy for the treatment of different types of cancer including renal, colorectal, lung and ovarian cancer, the restoration of normal blood vessels is temporally and spatially limited. TKIs bind other off-target kinases (74). Furthermore, VEGF inhibitors often fail to give enduring clinical responses, because they completely fail to respond (intrinsic resistance, a pre-existing condition defined by the absence of any beneficial effect of an anti-angiogenic therapy) or they initially respond and then continue growing while still receiving treatment (acquired resistance, caused by mutational alteration of the gene encoding a drug target or by alterations in drug uptake and efflux) (75). Finally, long-term antiangiogenic therapy may lead to tumour hypoxia (76). Thus, alternative approaches may be useful in the combat against tumours.
Cyclooxygenase-2 (COX-2) blockade. It is well established that there is a correlation between PLA2-COX expression and tumor cell proliferation as well as tumour proliferation and invasion (77-79). EC migration depends on PGE2 receptors (80), as their function is associated with VEGF secretion (81). In vitro studies demonstrated that glioma and retinoblastoma induced in EC an increase in inducible COX-2 protein expression, and prostaglandin E2 (PGE2) release (82,83) (Fig. 3). Clinical data indicate that antiangiogenic drugs induce tumour hypoxia, representing a high cause of stroma-mediated resistance in antiangiogenic therapies (84). This is the reason for which hypoxia-induced targets can be considered useful in surmounting antiangiogenic drug resistance. Upregulation of COX-2 during hypoxia induces angiogenesis via a distinct VEGF pathway and there is evidence that different COX-2 inhibitors are able to reduce tumourigenesis and tumour progression (85-87). For all these reasons, COX-2 inhibitors may improve the efficacy of antiangiogenic therapies by targeting an angiogenic pathway different from VEGF inhibitors.

In vitro and in vivo preclinical studies on mice showed that the upregulation of $\mathrm{COX}-2$ and the consequent high amount of PGE2 are related to tumour hypoxia and occur at standard levels of antiangiogenic drugs in breast cancer. The association of COX-2 inhibitor acetylsalicylic acid (ASA) and antiangiogenic drugs CD101 (anti-VEGFR2 mouse antibody) and sunitinib (VEGFR2 inhibitor) exerted additive anticancer effects, which occurs even at a lower than standard dose of antiangiogenic drugs alone, and additive antiangiogenic effects. ASA (but not sunitinib) was able to reduce the levels of proangiogenic cytokines IL-6 and HGF inside the tumour. Finally, the concomitant treatment with ASA and sunitinib blocked the infiltration of tumours with CAFs by interfering with AKT signalling (88).

The association of COX-2 inhibitors and antiangiogenic drugs may be an interesting strategy to improve the efficacy of antiangiogenic therapies in breast cancer and, possibly in other cancer types.

Targeting miRNAs. It is well known that miRNAs, small non-coding RNA that can suppress mRNA translation, are able to govern gene expression. Angiogenic processes and responses are finely regulated by miRNAs (examples of proangiogenic miRNAs: miR-126, let-7f, miR-27b; examples of antiangiogenic miRNAs: miR-20b, miR-21, miR-15a), and can be considered auspicious targets for potential therapeutics (Fig. 3) (89). Given that miRNAs bind to their target mRNAs, the usage of antimiRs could represent a way to target and inactivate pathological miRNAs (90).

In vitro studies on the use of antimiRs in cultured cells have been successful, so the goal of the research aimed at their development as a pharmacological target for in vivo utility was to study different strategies for the delivery of miRNA therapeutics.

These strategies include: i) antagomirs: oligonucleotides able to silence endogenous miRNAs, coniugated to cholesterol to facilitate cellular uptake; ii) locked nucleic acid- (LNA-) antimiRs: oligonucleotides with the ribose moiety of an LNA modified to improve specificity and stability and iii) miR-mask: modified 2'-O-methyl oligonucleotide complementary to the miRNA binding sites on the target mRNA (91-93). 


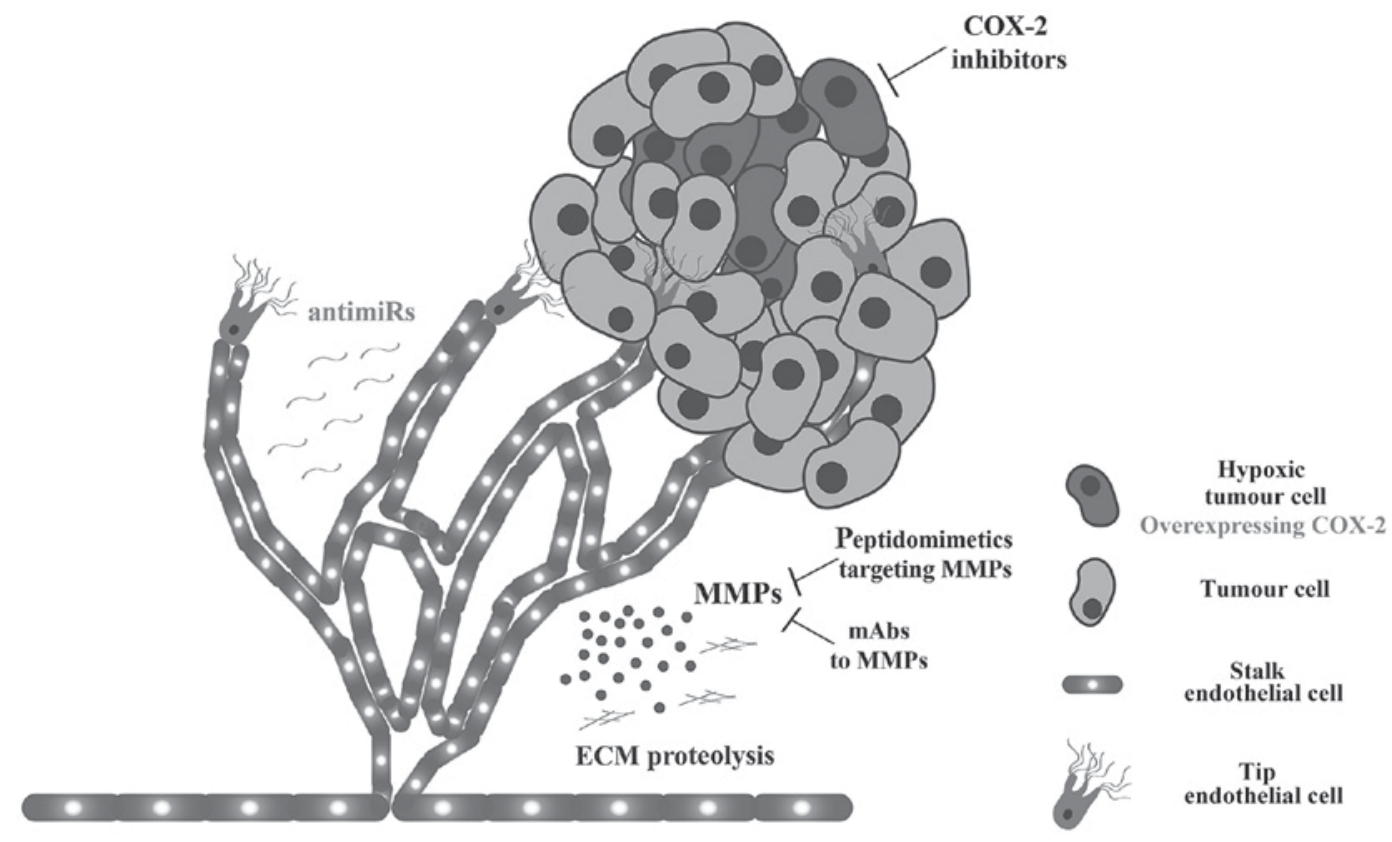

Figure 3. Alternative antiangiogenic therapies. The figure shows alternative antiangiogenic targets, different from the inhibition of VEGF, Notch and Ang pathways. Following antiangiogenic drugs, some tumour cells become hypoxic and overexpress COX-2, thereby inducing angiogenesis regardless of VEGF. For this reason, COX-2 constitutes an alternative antiangiogenic target. The upregulation of miRNAs (e.g., miR-17-92 and miR-126) during tumour growth and angiogenesis may be effectively counteracted by using of antimiRs, which are specific oligonucleotides complementary to the miRNAs. During angiogenesis, EC release MMPs to proteolyze the ECM. Breakdown of the ECM plays a pivotal role in tumour angiogenesis: targeting MMPs is a potential therapeutic solution. VEGF, vascular endothelial growth factor; COX-2, cyclooxygenase-2; EC, endothelial cells; MMPs, matrix metalloproteinases; ECM, extracellular matrix.

miRNAs can act as positive or negative modulators and bind to a plethora of different targets, thus the same miRNA can cause the opposite biological effect depending on the context. For this reason, it is crucial to select miRNAs able to bind to targets with the same required effect.

Components of miR-17-92 cluster are upregulated in solid tumours, such as non-small cell lung and colorectal cancer, and participate both in EC-mediated angiogenic and oncogenic functions $(94,95)$. So, in this case, targeting miR-17-92 cluster components is a good strategy for both antiangiogenic and antitumour therapy.

Since miR-126 is EC-specific, where it is requested for vascular integrity and angiogenesis $(96,97)$, it is a potential target for efficient antimiR therapy in situations of aberrant vascularization, including cancer and retinopathy.

However, there is no evidence in the introduction of miR-126 in non-ECs, and this emphasizes the importance of cell/tissue-specific miRNA targeting. To pursue this goal, an encouraging approach for miRNAs is the use of antibodies that can be internalized after their binding to cell-specific membrane receptors (98).

Thus, modification of miRNAs to pharmacological scopes is currently in the early stages, but constitutes an attractive strategy against the progression of tumour angiogenesis for future investigation.

Targeting matrix metalloproteinases (MMPs). The novel sprout of proliferating ECs during the angiogenesis process needs to break the extracellular matrix (ECM) to create a vessel network. Following their growth, ECs release proteases to proteolyze the ECM, mainly the MMPs, which are key enzymes playing a pivotal role in the breakdown of the ECM and tumour angiogenesis (Fig. 3) (99). Thus, a potential anticancer and antiangiogenic therapeutic solution is represented by their targeting. There are different strategies to inhibit these enzymes, including the use of compounds (e.g., antibodies, peptidomimetics, small molecules) able to compete with, sequester or inhibit MMP expression (100). However, to the best of our knowledge, MMP inhibitors are unsuccessful in clinical trials.

\section{VEGFA as a soluble biomarker in antiangiogenic therapy}

The National Institutes of Health (NIH) has defined a biomarker as 'a characteristic objectively measured and evaluated as an indicator of normal biologic processes, pathogenic processes, or pharmacologic responses to a therapeutic intervention' (101). There are prognostic biomarkers, useful to estimate the total disease outcome, independently of therapy, and predictive biomarkers, that provide information on the response of a specific therapy $(102,103)$.

The present review assessed the role of circulating VEGFA as a blood soluble predictive biomarker and its significance during antiangiogenic therapy in gastric, ovarian and colorectal cancer.

Biomarkers originating from tissues are ideal, but biopsies are difficult and invasive. The assessment of angiogenic parameters in blood by using classic immunogenic assays may 
be an interesting, non-invasive and cost-effective method of monitoring the effects of antiangiogenic therapies, which can be repeated over the course of treatment.

Gastric cancer. The correlation between VEGFA levels in the bloodstream and the response to VEGF inhibitor therapy in patients with gastric cancer showed complex and inconclusive results overall. In patients with extensive-stage gastric cancer from non-Asiatic regions during treatment with bevacizumab and chemotherapy, the levels of VEGFA correlated with bevacizumab effects in terms of survival. Therefore, changes in blood levels of VEGFA due to VEGF inhibition may be beneficial for patients (104). Conversely, patients from Asiatic regions tend to have lower baseline blood VEGFA levels and those with higher VEGFA level did not respond to VEGF inhibitor therapy (105). Additional trials including more patients are therefore required to clarify this ethnic-based discrepancy in VEGFA bloodstream levels.

Ovarian cancer. VEGFA levels in plasma or serum are higher in ovarian cancer with respect to benign ovarian neoplasms and correlates with advanced tumour stages and poor survival outcomes (106-108). Another study involving patients with ovarian cancer treated with bevacizumab showed that high baseline blood VEGFA levels were associated with a reduction of survival and an increased risk of death (109). However, the data remain to be confirmed in large-scale studies.

Colorectal cancer. The role of blood VEGFA levels as predictive biomarkers was evaluated in a few studies involving the efficacy of the antiangiogenic drug cediranib in metastatic colorectal cancer. High baseline VEGFA levels correlate with worsening progression-free and overall survival (110). However, these data have yet to be homogeneously confirmed and large-scale studies are needed. Thus, this information globally underlines the need for more biomarkers, which possibly also include molecular and clinical factors.

\section{Future directions}

Although anti-VEGF and conventional anti-angiogenic drugs are actually fundamental in anticancer therapies, many issues remain, including the limitations of drug resistance, the improvement of therapy efficacy, the development of strategies to reduce the mechanisms of resistance and toxicity, and the identification of new alternative antiangiogenic drugs. With regard to the latter concept, newly conceived nanosystems have been recently designed and developed as alternative and innovative strategies for the treatment of cancers by using anti-angiogenic pharmacological intervention (111). At present, new findings have been attributed to nanoparticle applications potential approaches in anti-angiogenic and antimetastasis research (112). Nanoparticles may be designed in order to carry out radioactive tracers, for gene and drug transporters $(113,114)$, showing notable advantages in releasing control, targeting and biosafety $(115,116)$. Several studies in in vitro and in vivo models have provided supporting evidence that silver nanoparticles (AgNPs) have both anticancer and anti-angiogenic properties (117). The AgNPs inhibit the VEGF-induced angiogenesis by blocking the formation of new microvessels through PI3K/AKT pathway inactivation (118). It has been demonstrated that the anionic clays layered double hydroxides (LDHs), a promising carrier for drug delivery according to their low cytotoxicity and high biocompatibility (119): their functionalized form with etoposide has showed anti-angiogenic activity in in vitro, ex-vivo and in vivo experimental models, eliciting depression of the PI3K-AKT and FAK-paxillin signaling pathways (120). Modified solid lipid nanoparticles loaded with paclitaxel were able to markedly reduce the tube formation in vitro and angiogenesis in vivo in glioma models (121), while, in a chorioallantoic membranes model system, pachymic acid modified multi-walled nanotubes caused a significant inhibition of angiogenesis and tube formation (122). Gold nanoparticles (AuNPs) as a drug-delivery system exhibit biocompatibility, low cytotoxicity (123), and the ability of delivering several molecules, including small drugs, proteins, DNA or RNA (124). AuNPs carry recombinant human endostatin have induced in vivo a transient tumour vascular normalization with the consequent enhancing the efficacy of anti-cancer molecules (125).

However, results from anti-angiogenic monotherapeutic clinical trials showed failures in significant responses or in improving overall survival (126). It has been observed that the canonical anti-angiogenic agents may enhance tumour invasiveness and metastasis in preclinical models (127). For these reasons, investigators created the new concept of 'tumour vascular normalization', according to which the anti-angiogenesis therapies markedly cause the chemo- and radioresistance of tumours, following the reduced flow of blood and the consequent oxygen supply, which, in turn, increase intratumour hypoxia (128). It has been suggested that the application of moderate doses of anti-angiogenic drugs may normalize aberrant tumour microvessels, thus improving blood perfusion and antitumour therapy (129). Aberrant tumour vessels are fenestrated with poor pericyte coverage, and this fact does not allow the chemotherapeutic molecule to reach the targeted tumour site. For this reason, it has been suggested that the association of an antitumour with an anti-angiogenic drug in a certain window of time may restore the imbalance between pro- and anti-angiogenic factors, leading to the normalization of blood vessels: this fact could allow the chemotherapeutic drug to reach the tumour (130).

\section{Conclusions}

The first generations of anti-angiogenic drugs, which have ameliorated progression-free survival and, in some cases, the survival for several tumour types, have been validated. On the other hand, these drugs have not been generally reconsidered in terms of new combinations, re-treatment strategies, and new timing administration. Thus, new comprehensive strategies using anti-angiogenic agents for the treatment of cancer are required. The validation of robust biomarkers able to screen the patients responsive to the treatments to better organize the clinical trials involving anti-angiogenic therapies is imperative.

\section{Acknowledgements}

We greatly thank Mr. Damiano Sgroi for the excellent support in the creation of images. 


\section{References}

1. Huang Y, Goel S, Duda DG, Fukumura D and Jain RK: Vascular normalization as an emerging strategy to enhance cancer immunotherapy. Cancer Res 73: 2943-2948, 2013.

2. Donnem T, Hu J, Ferguson M, Adighibe O, Snell C, Harris AL, Gatter KC and Pezzella F: Vessel co-option in primary human tumors and metastases: An obstacle to effective anti-angiogenic treatment? Cancer Med 2: 427-436, 2013

3. Folkman J: Tumor angiogenesis: Therapeutic implications. N Engl J Med 285: 1182-1186, 1971

4. Butler JM, Kobayashi H and Rafii S: Instructive role of the vascular niche in promoting tumour growth and tissue repair by angiocrine factors. Nat Rev Cancer 10: 138-146, 2010.

5. Hanahan D and Weinberg RA: The hallmarks of cancer. Cell 100: $57-70,2000$

6. Hanahan D and Folkman J: Patterns and emerging mechanisms of the angiogenic switch during tumorigenesis. Cell 86: 353-364, 1996.

7. Arbiser JL, Moses MA, Fernandez CA, Ghiso N, Cao Y, Klauber N, Frank D, Brownlee M, Flynn E, Parangi S, et al: Oncogenic $\mathrm{H}$-ras stimulates tumor angiogenesis by two distinct pathways. Proc Natl Acad Sci USA 94: 861-866, 1997.

8. Dameron KM, Volpert OV, Tainsky MA and Bouck N: Control of angiogenesis in fibroblasts by p53 regulation of thrombospondin-1. Science 265: 1582-1584, 1994.

9. Ferrara N and Kerbel RS: Angiogenesis as a therapeutic target. Nature 438: 967-974, 2005

10. Ferrara $\mathrm{N}$ and Adamis AP: Ten years of anti-vascular endothelial growth factor therapy. Nat Rev Drug Discov 15: 385-403, 2016

11. Soker S, Takashima S, Miao HQ, Neufeld G and Klagsbrun M: Neuropilin-1 is expressed by endothelial and tumor cells as an isoform-specific receptor for vascular endothelial growth factor. Cell 92: 735-745, 1998.

12. Olsson AK, Dimberg A, Kreuger J and Claesson-Welsh L: VEGF receptor signalling - in control of vascular function. Nat Rev Mol Cell Biol 7: 359-371, 2006.

13. LeCouter J, Moritz DR, Li B, Phillips GL, Liang XH, Gerber HP Hillan KJ and Ferrara N: Angiogenesis-independent endothelial protection of liver: Role of VEGFR-1. Science 299: 890-893, 2003.

14. Yao J, Wu X, Zhuang G, Kasman IM, Vogt T, Phan V, Shibuya M, Ferrara $\mathrm{N}$ and Bais C: Expression of a functional VEGFR-1 in tumor cells is a major determinant of anti-PIGF antibodies efficacy. Proc Natl Acad Sci USA 108: 11590-11595, 2011.

15. Chen JC, Chang YW, Hong CC, Yu YH and Su JL: The role of the VEGF-C/VEGFRs axis in tumor progression and therapy. Int J Mol Sci 14: 88-107, 2012

16. Jauhiainen S, Häkkinen SK, Toivanen PI, Heinonen SE, Jyrkkänen HK, Kansanen E, Leinonen H, Levonen AL and Ylä-Herttuala S: Vascular endothelial growth factor (VEGF)-D stimulates VEGF-A, stanniocalcin-1, and neuropilin-2 and has potent angiogenic effects. Arterioscler Thromb Vasc Biol 31: $1617-1624,2011$

17. Hicklin DJ and Ellis LM: Role of the vascular endothelial growth factor pathway in tumor growth and angiogenesis. J Clin Oncol 23: 1011-1027, 2005.

18. Jendreyko N, Popkov M, Rader C and Barbas CF III: Phenotypic knockout of VEGF-R2 and Tie-2 with an intradiabody reduces tumor growth and angiogenesis in vivo. Proc Natl Acad Sci USA 102: 8293-8298, 2005 .

19. Luo M, Hou L, Li J, Shao S, Huang S, Meng D, Liu L, Feng L, Xia P, Qin T, et al: VEGF/NRP-laxis promotes progression of breast cancer via enhancement of epithelial-mesenchymal transition and activation of NF- $\mathrm{NB}$ and $\beta$-catenin. Cancer Lett 373: $1-11,2016$

20. Koch S and Claesson-Welsh L: Signal transduction by vascular endothelial growth factor receptors. Cold Spring Harb Perspect Med 2: a006502-a006502, 2012.

21. Domigan CK, Ziyad S and Iruela-Arispe ML: Canonical and noncanonical vascular endothelial growth factor pathways: New developments in biology and signal transduction. Arterioscler Thromb Vasc Biol 35: 30-39, 2015.

22. Karkkainen MJ, Haiko P, Sainio K, Partanen J, Taipale J, Petrova TV, Jeltsch M, Jackson DG, Talikka M, Rauvala H, et al: Vascular endothelial growth factor $\mathrm{C}$ is required for sprouting of the first lymphatic vessels from embryonic veins. Nat Immunol 5: $74-80,2004$
23. Baldwin ME, Halford MM, Roufail S, Williams RA, Hibbs ML, Grail D, Kubo H, Stacker SA and Achen MG: Vascular endothelial growth factor D is dispensable for development of the lymphatic system. Mol Cell Biol 25: 2441-2449, 2005.

24. Haiko P, Makinen T, Keskitalo S, Taipale J, Karkkainen MJ, Baldwin ME, Stacker SA, Achen MG and Alitalo K: Deletion of vascular endothelial growth factor C (VEGF-C) and VEGF-D is not equivalent to VEGF receptor 3 deletion in mouse embryos. Mol Cell Biol 28: 4843-4850, 2008.

25. Liu Y, Cox SR, Morita T and Kourembanas S: Hypoxia regulates vascular endothelial growth factor gene expression in endothelial cells. Identification of a 5' enhancer. Circ Res 77: 638-643, 1995

26. Jochmanová I, Zelinka T, Widimský J Jr and Pacak K: HIF signaling pathway in pheochromocytoma and other neuroendocrine tumors. Physiol Res 63 (Suppl 2): S251-S262, 2014.

27. Ferrara N, Hillan KJ, Gerber HP and Novotny W: Discovery and development of bevacizumab, an anti-VEGF antibody for treating cancer. Nat Rev Drug Discov 3: 391-400, 2004.

28. Hurwitz H, Fehrenbacher L, Novotny W, Cartwright $T$, Hainsworth J, Heim W, Berlin J, Baron A, Griffing S, Holmgren E, et al: Bevacizumab plus irinotecan, fluorouracil, and leucovorin for metastatic colorectal cancer. N Engl J Med 350: 2335-2342, 2004.

29. Sandler A, Gray R, Perry MC, Brahmer J, Schiller JH, Dowlati A, Lilenbaum R and Johnson DH: Paclitaxel-carboplatin alone or with bevacizumab for non-small-cell lung cancer. N Engl J Med 355: 2542-2550, 2006.

30. Vredenburgh JJ, Desjardins A, Herndon JE II, Marcello J, Reardon DA, Quinn JA, Rich JN, Sathornsumetee S, Gururangan S, Sampson J, et al: Bevacizumab plus irinotecan in recurrent glioblastoma multiforme. J Clin Oncol 25: 4722-4729, 2007.

31. Escudier B, Bellmunt J, Négrier S, Bajetta E, Melichar B, Bracarda S, Ravaud A, Golding S, Jethwa S and Sneller V: Phase III trial of bevacizumab plus interferon alfa-2a in patients with metastatic renal cell carcinoma (AVOREN): Final analysis of overall survival. J Clin Oncol 28: 2144-2150, 2010.

32. Stockler MR, Hilpert F, Friedlander M, King MT, Wenzel L, Lee CK, Joly F, de Gregorio N, Arranz JA, Mirza MR, et al: Patient-reported outcome results from the open-label phase III AURELIA trial evaluating bevacizumab-containing therapy for platinum-resistant ovarian cancer. J Clin Oncol 32: 1309-1316, 2014.

33. Penson RT, Huang HQ, Wenzel LB, Monk BJ, Stockman S, Long HJ III, Ramondetta LM, Landrum LM, Oaknin A, Reid TJ, et al: Bevacizumab for advanced cervical cancer: Patient-reported outcomes of a randomised, phase 3 trial (NRG Oncology-Gynecologic Oncology Group protocol 240). Lancet Oncol 16: 301-311, 2015 .

34. Giurdanella G, Anfuso CD, Olivieri M, Lupo G, Caporarello N, Eandi CM, Drago F, Bucolo C, Salomone S: Aflibercept, bevacizumab and ranibizumab prevent glucose-induced damage in human retinal pericytes in vitro, through a $\mathrm{PLA}_{2} / \mathrm{COX}-2 / \mathrm{VEGF}-\mathrm{A}$ pathway. Biochem Pharmacol 96(3): 287-82, 2015

35. Ciombor KK and Berlin J: Aflibercept - a decoy VEGF receptor. Curr Oncol Rep 16: 368, 2014.

36. Papadopoulos N, Martin J, Ruan Q, Rafique A, Rosconi MP, Shi E, Pyles EA, Yancopoulos GD, Stahl N and Wiegand SJ: Binding and neutralization of vascular endothelial growth factor (VEGF) and related ligands by VEGF Trap, ranibizumab and bevacizumab. Angiogenesis 15: 171-185, 2012.

37. Van Cutsem E, Tabernero J, Lakomy R, Prenen H, Prausová J, Macarulla T, Ruff P, van Hazel GA, Moiseyenko V, Ferry D, et al: Addition of aflibercept to fluorouracil, leucovorin, and irinotecan improves survival in a phase III randomized trial in patients with metastatic colorectal cancer previously treated with an oxaliplatin-based regimen. J Clin Oncol 30: 3499-3506, 2012.

38. Gotink KJ and Verheul HM: Anti-angiogenic tyrosine kinase inhibitors: What is their mechanism of action? Angiogenesis 13: 1-14, 2010.

39. Bhargava P and Robinson MO: Development of second-generation VEGFR tyrosine kinase inhibitors: Current status. Curr Oncol Rep 13: 103-111, 2011.

40. Demetri GD, van Oosterom AT, Garrett CR, Blackstein ME, Shah MH, Verweij J, McArthur G, Judson IR, Heinrich MC, Morgan JA, et al: Efficacy and safety of sunitinib in patients with advanced gastrointestinal stromal tumour after failure of imatinib: A randomised controlled trial. Lancet 368: 1329-1338, 2006. 
41. Llovet JM, Ricci S, Mazzaferro V, Hilgard P, Gane E, Blanc JF, de Oliveira AC, Santoro A, Raoul JL, Forner A, et al; SHARP Investigators Study Group: Sorafenib in advanced hepatocellular carcinoma. N Engl J Med 359: 378-390, 2008.

42. Motzer RJ, Hutson TE, Tomczak P, Michaelson MD, Bukowski RM, Oudard S, Negrier S, Szczylik C, Pili R, Bjarnason GA, et al: Overall survival and updated results for sunitinib compared with interferon alfa in patients with metastatic renal cell carcinoma. J Clin Oncol 27: 3584-3590, 2009.

43. Duda DG: Molecular biomarkers of response to antiangiogenic therapy for cancer. ISRN Cell Biol 2012: 587259, 2012.

44. Raymond E, Dahan L, Raoul JL, Bang YJ, Borbath I Lombard-Bohas C, Valle J, Metrakos P, Smith D, Vinik A, et al: Sunitinib malate for the treatment of pancreatic neuroendocrine tumors. N Engl J Med 364: 501-513, 2011.

45. Ranieri G, Mammì M, Donato Di Paola E, Russo E, Gallelli L, Citraro R, Gadaleta CD, Marech I, Ammendola M and De Sarro G: Pazopanib a tyrosine kinase inhibitor with strong anti-angiogenetic activity: A new treatment for metastatic sof tissue sarcoma. Crit Rev Oncol Hematol 89: 322-329, 2014.

46. Wilke H, Muro K, Van Cutsem E, Oh SC, Bodoky G, Shimada Y, Hironaka S, Sugimoto N, Lipatov O, Kim TY, et al; RAINBOW Study Group: Ramucirumab plus paclitaxel versus placebo plus paclitaxel in patients with previously treated advanced gastric or gastro-oesophageal junction adenocarcinoma (RAINBOW): A double-blind, randomised phase 3 trial. Lancet Oncol 15 1224-1235, 2014.

47. Garon EB, Ciuleanu TE, Arrieta O, Prabhash K, Syrigos KN, Goksel T, Park K, Gorbunova V, Kowalyszyn RD, Pikiel J, et al: Ramucirumab plus docetaxel versus placebo plus docetaxel for second-line treatment of stage IV non-small-cell lung cancer after disease progression on platinum-based therapy (REVEL): A multicentre, double-blind, randomised phase 3 trial. Lancet 384 : 665-673, 2014

48. Fuchs CS, Tomasek J, Yong CJ, Dumitru F, Passalacqua R, Goswami C, Safran H, dos Santos LV, Aprile G, Ferry DR, et al; REGARD Trial Investigators: Ramucirumab monotherapy for previously treated advanced gastric or gastro-oesophageal junction adenocarcinoma (REGARD): An international, randomised, multicentre, placebo-controlled, phase 3 trial. Lancet 383: 31-39, 2014

49. Tabernero J, Yoshino T, Cohn AL, Obermannova R, Bodoky G, Garcia-Carbonero R, Ciuleanu TE, Portnoy DC, Van Cutsem E, Grothey A, et al; RAISE Study Investigators: Ramucirumab versus placebo in combination with second-line FOLFIRI in patients with metastatic colorectal carcinoma that progressed during or after first-line therapy with bevacizumab, oxaliplatin and a fluoropyrimidine (RAISE): A randomised, double-blind, multicentre, phase 3 study. Lancet Oncol 16: 499-508, 2015.

50. Mackey JR, Ramos-Vazquez M, Lipatov O, McCarthy N, Krasnozhon D, Semiglazov V, Manikhas A, Gelmon KA, Konecny GE, Webster M, et al: Primary results of ROSE-TRIO-12, a randomized placebo-controlled phase III trial evaluating the addition of ramucirumab to first-line docetaxel chemotherapy in metastatic breast cancer. J Clin Oncol 33: 141-148, 2015.

51. Zhu AX, Park JO, Ryoo BY, Yen CJ, Poon R, Pastorelli D, Blanc JF, Chung HC, Baron AD, Pfiffer TE, et al; REACH Trial Investigators: Ramucirumab versus placebo as second-line treatment in patients with advanced hepatocellular carcinoma following first-line therapy with sorafenib (REACH): A randomised, double-blind, multicentre, phase 3 trial. Lancet Oncol 16: 859-870, 2015

52. Calvetti L, Pilotto S, Carbognin L, Ferrara R, Caccese M, Tortora $\mathrm{G}$ and Bria E: The coming of ramucirumab in the landscape of anti-angiogenic drugs: Potential clinical and translational perspectives. Expert Opin Biol Ther 15: 1359-1370, 2015.

53. Kuhnert F, Kirshner JR and Thurston G: Dll4-Notch signaling as a therapeutic target in tumor angiogenesis. Vasc Cell 3: 20, 2011.

54. Iso T, Hamamori $\mathrm{Y}$ and Kedes L: Notch signaling in vascular development. Arterioscler Thromb Vasc Biol 23: 543-553, 2003.

55. Hellström M, Phng LK, Hofmann JJ, Wallgard E, Coultas L, Lindblom P, Alva J, Nilsson AK, Karlsson L, Gaiano N, et al: Dll4 signalling through Notch1 regulates formation of tip cells during angiogenesis. Nature 445: 776-780, 2007.

56. Patel NS, Li JL, Generali D, Poulsom R, Cranston DW and Harris AL: Up-regulation of delta-like 4 ligand in human tumor vasculature and the role of basal expression in endothelial cell function. Cancer Res 65: 8690-8697, 2005
57. Mailhos C, Modlich U, Lewis J, Harris A, Bicknell R and Ish-Horowicz D: Delta4, an endothelial specific notch ligand expressed at sites of physiological and tumor angiogenesis. Differentiation 69: 135-144, 2001.

58. Ridgway J, Zhang G, Wu Y, Stawicki S, Liang WC, Chanthery Y, Kowalski J, Watts RJ, Callahan C, Kasman I, et al: Inhibition of Dl14 signalling inhibits tumour growth by deregulating angiogenesis. Nature 444: 1083-1087, 2006.

59. Noguera-Troise I, Daly C, Papadopoulos NJ, Coetzee S, Boland P, Gale NW, Lin HC, Yancopoulos GD and Thurston G: Blockade of Dll4 inhibits tumour growth by promoting non-productive angiogenesis. Nature 444: 1032-1037, 2006.

60. Scehnet JS, Jiang W, Kumar SR, Krasnoperov V, Trindade A, Benedito R, Djokovic D, Borges C, Ley EJ, Duarte A, et al: Inhibition of Dll4-mediated signaling induces proliferation of immature vessels and results in poor tissue perfusion. Blood 109: 4753-4760, 2007

61. Funahashi Y, Hernandez SL, Das I, Ahn A, Huang J, Vorontchikhina M, Sharma A, Kanamaru E, Borisenko V, Desilva DM, et al: A notch1 ectodomain construct inhibits endothelial notch signaling, tumor growth, and angiogenesis. Cancer Res 68: 4727-4735, 2008

62. Kangsamaksin T, Murtomaki A, Kofler NM, Cuervo H, Chaudhri RA, Tattersall IW, Rosenstiel PE, Shawber CJ and Kitajewski J: NOTCH decoys that selectively block DLL/NOTCH or JAG/NOTCH disrupt angiogenesis by unique mechanisms to inhibit tumor growth. Cancer Discov 5: 182-197, 2015.

63. Olsauskas-Kuprys R, Zlobin A and Osipo C: Gamma secretase inhibitors of Notch signaling. Onco Targets Ther 6: 943-955, 2013.

64. Augustin HG, Koh GY, Thurston G and Alitalo K: Control of vascular morphogenesis and homeostasis through the angiopoietin-Tie system. Nat Rev Mol Cell Biol 10: 165-177, 2009.

65. Thurston G, Rudge JS, Ioffe E, Zhou H, Ross L, Croll SD, Glazer N, Holash J, McDonald DM and Yancopoulos GD: Angiopoietin-1 protects the adult vasculature against plasma leakage. Nat Med 6: 460-463, 2000

66. Tait CR and Jones PF: Angiopoietins in tumours: The angiogenic switch. J Pathol 204: 1-10, 2004.

67. Scharpfenecker M, Fiedler U, Reiss Y and Augustin HG: The Tie-2 ligand angiopoietin-2 destabilizes quiescent endothelium through an internal autocrine loop mechanism. J Cell Sci 118: 771-780, 2005

68. Leow CC, Coffman K, Inigo I, Breen S, Czapiga M, Soukharev S, Gingles N, Peterson N, Fazenbaker C, Woods R, et al: MEDI3617, a human anti-angiopoietin 2 monoclonal antibody, inhibits angiogenesis and tumor growth in human tumor xenograft models. Int J Oncol 40: 1321-1330, 2012

69. Daly C, Eichten A, Castanaro C, Pasnikowski E, Adler A, Lalani AS, Papadopoulos N, Kyle AH, Minchinton AI, Yancopoulos GD, et al: Angiopoietin-2 functions as a Tie2 agonist in tumor models, where it limits the effects of VEGF inhibition. Cancer Res 73: 108-118, 2013.

70. Kienast Y, Klein C, Scheuer W, Raemsch R, Lorenzon E, Bernicke D, Herting F, Yu S, The HH, Martarello L, et al: Ang-2-VEGF-A CrossMab, a novel bispecific human IgG1 antibody blocking VEGF-A and Ang-2 functions simultaneously, mediates potent antitumor, antiangiogenic, and antimetastatic efficacy. Clin Cancer Res 19: 6730-6740, 2013.

71. Oliner J, Min H, Leal J, Yu D, Rao S, You E, Tang X, Kim H, Meyer S, Han SJ, et al: Suppression of angiogenesis and tumor growth by selective inhibition of angiopoietin-2. Cancer Cell 6: 507-516, 2004.

72. Monk BJ, Poveda A, Vergote I, Raspagliesi F, Fujiwara K, Bae DS, Oaknin A, Ray-Coquard I, Provencher DM, Karlan BY, et al: Anti-angiopoietin therapy with trebananib for recurrent ovarian cancer (TRINOVA-1): A randomised, multicentre, double-blind, placebo-controlled phase 3 trial. Lancet Oncol 15: 799-808, 2014.

73. Brindle NP, Sale JE, Arakawa H, Buerstedde JM, Nuamchit T, Sharma S and Steele KH: Directed evolution of an angiopoietin-2 ligand trap by somatic hypermutation and cell surface display. J Biol Chem 288: 33205-33212, 2013.

74. Schmidinger $\mathrm{M}$ and Bellmunt J: Plethora of agents, plethora of targets, plethora of side effects in metastatic renal cell carcinoma. Cancer Treat Rev 36: 416-424, 2010.

75. Bergers $G$ and Hanahan D: Modes of resistance to anti-angiogenic therapy. Nat Rev Cancer 8: 592-603, 2008. 
76. Winkler F, Kozin SV, Tong RT, Chae SS, Booth MF, Garkavtsev I, Xu L, Hicklin DJ, Fukumura D, di Tomaso E, et al: Kinetics of vascular normalization by VEGFR2 blockade governs brain tumor response to radiation: Role of oxygenation, angiopoietin-1, and matrix metalloproteinases. Cancer Cell 6: $553-563,2004$

77. Anfuso CD, Giurdanella G, Motta C, Muriana S, Lupo G, Ragusa N and Alberghina M: PKC $\alpha$-MAPK/ERK-phospholipase $\mathrm{A}_{2}$ signaling is required for human melanoma-enhanced brain endothelial cell proliferation and motility. Microvasc Res 78: 338-357, 2009.

78. Scuderi MR, Anfuso CD, Lupo G, Motta C, Romeo L, Guerra L, Cappellani A, Ragusa N, Cantarella G and Alberghina M: Expression of $\mathrm{Ca}^{2+}$-independent and $\mathrm{Ca}^{2+}$-dependent phospholipases $\mathrm{A}_{2}$ and cyclooxygenases in human melanocytes and malignant melanoma cell lines. Biochim Biophys Acta 1781: 635-642, 2008

79. Lupo G, Anfuso CD, Ragusa N, Tirolo C, Marchetti B, Gili E, La Rosa C and Vancheri C: Activation of cytosolic phospholipase $\mathrm{A}_{2}$ and 15-lipoxygenase by oxidized low-density lipoproteins in cultured human lung fibroblasts. Biochim Biophys Acta 1771: 522-532, 2007

80. Rao R, Redha R, Macias-Perez I, Su Y, Hao C, Zent R, Breyer MD and Pozzi A: Prostaglandin E2-EP4 receptor promotes endothelial cell migration via ERK activation and angiogenesis in vivo. J Biol Chem 282: 16959-16968, 2007.

81. Pai R, Szabo IL, Soreghan BA, Atay S, Kawanaka H and Tarnawski AS: PGE 2 stimulates VEGF expression in endothelial cells via ERK2/JNK1 signaling pathways. Biochem Biophys Res Commun 286: 923-928, 2001.

82. Lupo G, Motta C, Salmeri M, Spina-Purrello V, Alberghina M and Anfuso CD: An in vitro retinoblastoma human triple culture model of angiogenesis: A modulatory effect of TGF- $\beta$. Cancer Lett 354: 181-188, 2014

83. Anfuso CD, Motta C, Giurdanella G, Arena V, Alberghina M and Lupo G: Endothelial PKC $\alpha$-MAPK/ERK-phospholipase $\mathrm{A}_{2}$ pathway activation as a response of glioma in a triple culture model. A new role for pericytes? Biochimie 99: 77-87, 2014.

84. Maione F, Capano S, Regano D, Zentilin L, Giacca M, Casanovas O, Bussolino F, Serini G and Giraudo E: Semaphorin 3A overcomes cancer hypoxia and metastatic dissemination induced by antiangiogenic treatment in mice. J Clin Invest 122: 1832-1848, 2012.

85. Howe LR, Subbaramaiah K, Patel J, Masferrer JL, Deora A, Hudis C, Thaler HT, Muller WJ, Du B, Brown AM, et al: Celecoxib, a selective cyclooxygenase 2 inhibitor, protects against human epidermal growth factor receptor 2 (HER-2)/neu-induced breast cancer. Cancer Res 62: 5405-5407, 2002.

86. Yoshinaka R, Shibata MA, Morimoto J, Tanigawa N and Otsuki Y: COX-2 inhibitor celecoxib suppresses tumor growth and lung metastasis of a murine mammary cancer. Anticancer Res 26 (6B): 4245-4254, 2006

87. Connolly EM, Harmey JH, O'Grady T, Foley D, Roche-Nagle G, Kay E and Bouchier-Hayes DJ: Cyclo-oxygenase inhibition reduces tumour growth and metastasis in an orthotopic model of breast cancer. Br J Cancer 87: 231-237, 2002.

88. Ben-Batalla I, Cubas-Cordova M, Udonta F, Wroblewski M, Waizenegger JS, Janning M, Sawall S, Gensch V, Zhao L, Martinez-Zubiaurre I, et al: Cyclooxygenase-2 blockade can improve efficacy of VEGF-targeting drugs. Oncotarget 6 : 6341-6358, 2015

89. Gallach S, Calabuig-Fariñas S, Jantus-Lewintre E and Camps C: MicroRNAs: Promising new antiangiogenic targets in cancer. BioMed Res Int 2014: 878450, 2014

90. Davis S, Lollo B, Freier S and Esau C: Improved targeting of miRNA with antisense oligonucleotides. Nucleic Acids Res 34 2294-2304, 2006

91. Elmén J, Lindow M, Schütz S, Lawrence M, Petri A, Obad S Lindholm M, Hedtjärn M, Hansen $\mathrm{HF}$, Berger $\mathrm{U}$, et al: LNA-mediated microRNA silencing in non-human primates. Nature 452: 896-899, 2008

92. Esau C, Davis S, Murray SF, Yu XX, Pandey SK, Pear M Watts L, Booten SL, Graham M, McKay R, et al: miR-122 regulation of lipid metabolism revealed by in vivo antisense targeting. Cell Metab 3: 87-98, 2006

93. Krützfeldt J, Rajewsky N, Braich R, Rajeev KG, Tuschl T, Manoharan M and Stoffel M: Silencing of microRNAs in vivo with 'antagomirs'. Nature 438: 685-689, 2005.
94. Suárez Y,Fernández-Hernando C, Yu J, Gerber SA, Harrison KD, Pober JS, Iruela-Arispe ML, Merkenschlager M and Sessa WC: Dicer-dependent endothelial microRNAs are necessary for postnatal angiogenesis. Proc Natl Acad Sci USA 105: 1408214087,2008

95. Wiemer EA: The role of microRNAs in cancer: No small matter. Eur J Cancer 43: 1529-1544, 2007.

96. Fish JE, Santoro MM, Morton SU, Yu S, Yeh RF, Wythe JD, Ivey KN, Bruneau BG, Stainier DY and Srivastava D: miR-126 regulates angiogenic signaling and vascular integrity. Dev Cell 15: 272-284, 2008.

97. Wang S, Aurora AB, Johnson BA, Qi X, McAnally J, Hill JA, Richardson JA, Bassel-Duby R and Olson EN: The endothelial-specific microRNA miR-126 governs vascular integrity and angiogenesis. Dev Cell 15: 261-271, 2008

98. Song E, Zhu P, Lee SK, Chowdhury D, Kussman S, Dykxhoorn DM, Feng Y, Palliser D, Weiner DB, Shankar P, et al: Antibody mediated in vivo delivery of small interfering RNAs via cell-surface receptors. Nat Biotechnol 23: 709-717, 2005.

99. Lu P, Takai K, Weaver VM and Werb Z: Extracellular matrix degradation and remodeling in development and disease. Cold Spring Harb Perspect Biol 1: 3, 2011.

100. Finley SD, Chu LH and Popel AS: Computational systems biology approaches to anti-angiogenic cancer therapeutics. Drug Discov Today 20: 187-197, 2015.

101. De Gruttola VG, Clax P, DeMets DL, Downing GJ, Ellenberg SS, Friedman L, Gail MH, Prentice R, Wittes J and Zeger SL: Considerations in the evaluation of surrogate endpoints in clinical trials: Summary of a National Institutes of Health workshop. Control Clin Trials 22: 485-502, 2001.

102. Oldenhuis CN, Oosting SF, Gietema JA and de Vries EG: Prognostic versus predictive value of biomarkers in oncology. Eur J Cancer 44: 946-953, 2008.

103. McShane LM, Altman DG, Sauerbrei W, Taube SE, Gion M and Clark GM; Statistics Subcommittee of the NCI-EORTC Working Group on Cancer Diagnostics: Reporting recommendations for tumor marker prognostic studies (REMARK). J Natl Cancer Inst 97: 1180-1184, 2005.

104. Van Cutsem E, de Haas S, Kang YK, Ohtsu A, Tebbutt NC, Ming Xu J, Peng Yong W, Langer B, Delmar P, Scherer SJ, et al: Bevacizumab in combination with chemotherapy as first-line therapy in advanced gastric cancer: A biomarker evaluation from the AVAGAST randomized phase III trial. J Clin Oncol 30: 2119-2127, 2012.

105. Jia S and Cai J: Update on biomarkers in development of anti-angiogenic drugs in gastric cancer. Anticancer Res 36: $1111-1118,2016$

106. Cooper BC, Ritchie JM, Broghammer CL, Coffin J, Sorosky JI, Buller RE, Hendrix MJ and Sood AK: Preoperative serum vascular endothelial growth factor levels: Significance in ovarian cancer. Clin Cancer Res 8: 3193-3197, 2002.

107. Kassim SK, El-Salahy EM, Fayed ST, Helal SA, Helal T, Azzam E-D and Khalifa A: Vascular endothelial growth factor and interleukin- 8 are associated with poor prognosis in epithelial ovarian cancer patients. Clin Biochem 37: 363-369, 2004.

108. Li L, Wang L, Zhang W, Tang B, Zhang J, Song H, Yao D, Tang Y, Chen X, Yang Z, et al: Correlation of serum VEGF levels with clinical stage, therapy efficacy, tumor metastasis and patient survival in ovarian cancer. Anticancer Res 24 (3b): 1973-1979, 2004.

109. Secord AA, Nixon AB and Hurwitz HI: The search for biomarkers to direct antiangiogenic treatment in epithelial ovarian cancer. Gynecol Oncol 135: 349-358, 2014.

110. Mousa L, Salem ME and Mikhail S: Biomarkers of angiogenesis in colorectal cancer. Biomark Cancer 7 (Suppl 1): 13-19, 2015.

111. Mukherjee S and Patra CR: Therapeutic application of anti-angiogenic nanomaterials in cancers. Nanoscale 8: 12444-12470, 2016

112. Patil R, Ljubimov AV, Gangalum PR, Ding H, Portilla-Arias J, Wagner S, Inoue S, Konda B, Rekechenetskiy A, Chesnokova A, et al: MRI virtual biopsy and treatment of brain metastatic tumors with targeted nanobioconjugates: Nanoclinic in the brain. ACS Nano 9: 5594-5608, 2015.

113. Salvati A, Pitek AS, Monopoli MP, Prapainop K, Bombelli FB, Hristov DR, Kelly PM, Äberg C, Mahon E and Dawson KA: Transferrin-functionalized nanoparticles lose their targeting capabilities when a biomolecule corona adsorbs on the surface. Nat Nanotechnol 8: 137-143, 2013. 
114. Karra N and Benita S: The ligand nanoparticle conjugation approach for targeted cancer therapy (Review). Curr Drug Metab 13: 22-41, 2012.

115. Agostinelli E, Vianello F, Magliulo G, Thomas $T$ and Thomas TJ: Nanoparticle strategies for cancer therapeutics: Nucleic acids, polyamines, bovine serum amine oxidase and iron oxide nanoparticles (Review). Int J Oncol 46: 5-16, 2015.

116. Agostinelli E, Tempera G, Viceconte N, Saccoccio S, Battaglia V, Grancara S, Toninello A and Stevanato R: Potential anticancer application of polyamine oxidation products formed by amine oxidase: A new therapeutic approach. Amino Acids 38: 353-368, 2010.

117.Zhang XF, Liu ZG, Shen W and Gurunathan S: Silver nanoparticles: Synthesis, characterization, properties, applications, and therapeutic approaches (Review). Int J Mol Sci 17: pii: E1534, 2016.

118. Gurunathan S, Lee KJ, Kalishwaralal K, Sheikpranbabu S, Vaidyanathan R and Eom SH: Antiangiogenic properties of silver nanoparticles. Biomaterials 30: 6341-6350, 2009

119. Theiss FL, Couperthwaite SJ, Ayoko GA and Frost RL: A review of the removal of anions and oxyanions of the halogen elements from aqueous solution by layered double hydroxides. J Colloid Interface Sci 417: 356-368, 2014.

120.Zhu Y, Zhu R, Wang M, Wu B, He X, Qian Y and Wang S: Anti-metastatic and anti-angiogenic activities of core-shell $\mathrm{SiO}_{2} @ \mathrm{LDH}$ loaded with etoposide in non-small cell lung cancer. Adv Sci Weinh 3: 1600229, 2016.

121. Banerjee I, De K, Mukherjee D, Dey G, Chattopadhyay S, Mukherjee M, Mandal M, Bandyopadhyay AK, Gupta A, Ganguly S, et al: Paclitaxel-loaded solid lipid nanoparticles modified with Tyr-3-octreotide for enhanced anti-angiogenic and anti-glioma therapy. Acta Biomater 38: 69-81, 2016.

122. Ma J, Liu J, Lu CW and Cai DF: Pachymic acid modified carbon nanoparticles reduced angiogenesis via inhibition of MMP-3. Int J Clin Exp Pathol 8: 5464-5470, 2015.
123. Pan Y, Wu Q, Liu R, Shao M, Pi J, Zhao X and Qin L: Inhibition effects of gold nanoparticles on proliferation and migration in hepatic carcinoma-conditioned HUVECs. Bioorg Med Chem Lett 24: 679-684, 2014.

124. Iosin M, Toderas F, Baldeck PL and Astilean S: Study of protein-gold nanoparticle conjugates by fluorescence and surface-enhanced Raman scattering. J Mol Struct 924-926: 196-200, 2009.

125.Li W, Zhao X, Du B, Li X, Liu S, Yang XY, Ding H, Yang W, Pan F, Wu X, et al: Gold Nanoparticle-mediated targeted delivery of recombinant human endostatin normalizes tumour vasculature and improves cancer therapy. Sci Rep 6: 30619 , 2016.

126. Jain RK, Duda DG, Clark JW and Loeffler JS: Lessons from phase III clinical trials on anti-VEGF therapy for cancer (Review). Nat Clin Pract Oncol 3: 24-40, 2006.

127. Pàez-Ribes M, Allen E, Hudock J, Takeda T, Okuyama H, Viñals F, Inoue M, Bergers G, Hanahan D and Casanovas O: Antiangiogenic therapy elicits malignant progression of tumors to increased local invasion and distant metastasis. Cancer Cell 15: 220-231, 2009.

128. Ebos JM, Lee CR, Cruz-Munoz W, Bjarnason GA, Christensen JG and Kerbel RS: Accelerated metastasis after short-term treatment with a potent inhibitor of tumor angiogenesis. Cancer Cell 15: 232-239, 2009.

129. Chatterjee S, Wieczorek C, Schöttle J, Siobal M, Hinze Y, Franz T, Florin A, Adamczak J, Heukamp LC, Neumaier B, et al: Transient antiangiogenic treatment improves delivery of cytotoxic compounds and therapeutic outcome in lung cancer. Cancer Res 74: 2816-2824, 2014.

130. Lupo G, Caporarello N, Olivieri M, Cristaldi M, Motta C, Bramanti V, Avola R, Salmeri M, Nicoletti F and Anfuso CD: Anti-angiogenic therapy in cancer: Downsides and new pivots for precision medicine (Review). Front Pharmacol 7: 519, 2017. 